An International Journal at the Interface Between Chemistry and Physics

\title{
A bonding evolution theory study on the catalytic Noyori hydrogenation reaction
}

\author{
Julen Munárriz, Ruben Laplaza \& Víctor Polo
}

To cite this article: Julen Munárriz, Ruben Laplaza \& Víctor Polo (2018): A bonding evolution theory study on the catalytic Noyori hydrogenation reaction, Molecular Physics, DOI: $\underline{10.1080 / 00268976.2018 .1542168}$

To link to this article: https://doi.org/10.1080/00268976.2018.1542168

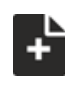

View supplementary material ¿

果

Published online: 01 Nov 2018.

Submit your article to this journal $[\pi$

Џlll Article views: 16

View Crossmark data ־ 


\title{
A bonding evolution theory study on the catalytic Noyori hydrogenation reaction
}

\author{
Julen Munárriz ${ }^{\mathrm{a}}$, Ruben Laplaza ${ }^{\mathrm{a}, \mathrm{b}}$ and Víctor Polo ${ }^{\mathrm{a}}$ \\ ${ }^{a}$ Departamento de Química Física and Instituto de Biocomputación y Física de los Sistemas Complejos (BIFI), Universidad de Zaragoza, \\ Zaragoza, Spain; 'b Sorbonne Université, CNRS, Laboratoire de Chimie Théorique, LCT, Paris, France
}

\begin{abstract}
The electronic rearrangements involved in Noyori hydrogenation reactions with double bonds (ethene and formaldehyde) are analysed using the bonding evolution theory. The study and analysis of the changes on the electron localisation function topology along a given reaction path reveals fluxes of electron density, allowing to unambiguously identify the main chemical events happening along the chemical reactions. This analysis shows that the first hydrogen transfer (with hydride character) occurs before the transition state (TS), while the second hydrogen transfer (with proton character) takes places after having reached the TS. The lower energy barrier found for formaldehyde over ethene is explained by two reasons. First, the hydride transfer is favoured for the $\mathrm{C}=\mathrm{O}$ bond over $\mathrm{C}=\mathrm{C}$ due to the electrophilic character of the carbon atom. Second, a negatively charged $\mathrm{CH}_{3}-X\left(X=\mathrm{CH}_{2}, \mathrm{O}\right)$ hidden intermediate is formed in the proximities of the TS region. The oxygen atom is able to stabilise this negatively charged species more effectively than the $\mathrm{CH}_{2}$ group due to its higher electronegativity and the presence of $\mathrm{V}(\mathrm{O})$ lone pairs. The obtained analysis explains and rationalises catalyst chemoselectivity $(C=O$ vs. $C=C)$. Finally, a curly arrow representation diagram accounting for the electronic rearrangements is proposed on the basis of BET results.
\end{abstract}
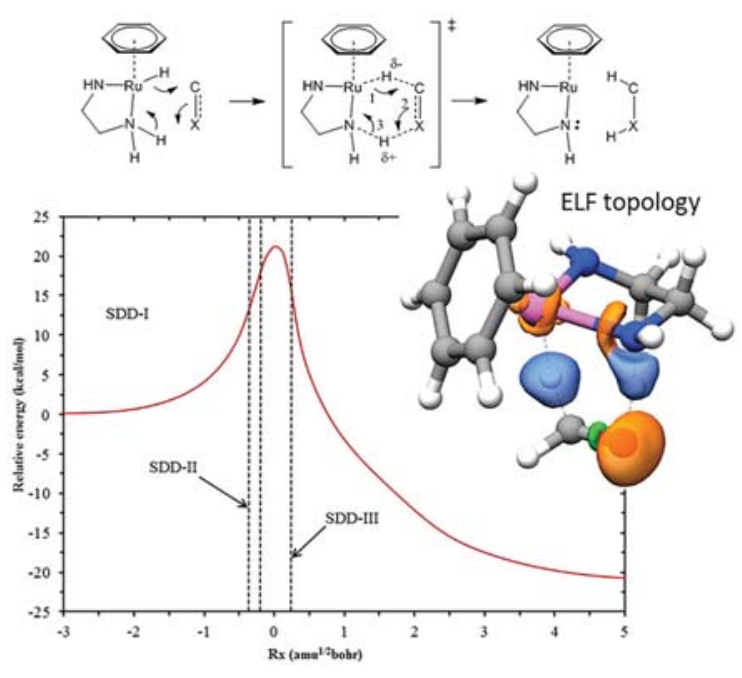

\section{ARTICLE HISTORY}

Received 8 September 2018

Accepted 16 October 2018

\section{KEYWORDS}

\section{DFT calculations;}

organometallic chemistry; electron localisation function (ELF); catastrophe theory;

bonding evolution theory

\section{Introduction}

The Noyori-type metal-NH bifunctional catalyst opened the door towards a new type of efficient catalysts; enabling the hydrogenation of ketones with low catalyst loading, high $\mathrm{C}=\mathrm{O} / \mathrm{C}=\mathrm{C}$ chemoselectivity and enantioselectivity (achieved using chiral ligands) [1-4].
Numerous experimental and theoretical studies have been devoted to understand the mechanistic details of this transformation, pursuing the development of novel catalysts based on the metal-ligand bifunctional concept [5]. The reaction mechanism is described as an outer sphere one, without direct coordination of the substrate

CONTACTVíctorPolo vipolo@unizar.es $\Theta$ c/Pedro Cerbuna s/n 50009, Zaragoza, Spain

(4) Supplemental data for this article can be accessed here. https://doi.org/10.1080/00268976.2018.1542168 


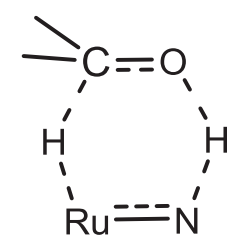

Scheme 1. Six-membered pericyclic transition state for the transfer hydrogenation of ketones.

to the metal, where the hydride from the ruthenium and the proton from the amine are delivered directly to the ketone. Using gas-phase calculations, a rate-determining pericyclic transition state [6-10] was proposed, as shown in Scheme 1. However, the inclusion of specific and nonspecific solvation effects by Dub and Ikariya [11] showed that reaction proceeds via a two-step process, involving an ion-pair intermediate. This new mechanistic proposal in solution is defined by (i) hydride transfer from the metal followed by (ii) proton transfer to the $\mathrm{N}-\mathrm{H}$ ligand through the contact ion-pair intermediate. Interestingly, the proton transfer can be either from the amine group or from a protic solvent. As a consequence, the function of the ligand in this type of metal-ligand bifunctional catalysts would not only be acting as a proton donor but also stabilising the transition state by hydrogen bonding interactions [12].

In addition to accurate calculation of stationary points on the potential energy surface, the design of new organometallic complexes with improved catalytic properties requires a detailed understanding of the electronic factors controlling the energetic barriers of all relevant processes involved in the reaction mechanism [13]. Therefore, a complete unambiguous characterisation of the chemical bond breaking/formation in such complex systems is required. Nowadays, several methodologies are able to analyse the changes of different molecular properties along a given reaction path. Among them, especially remarkable Unified Reaction Valley Approach is proposed by Cremer [14]. This approach employs the reaction path curvature in conjunction with internal coordinate decomposition as a tool for identifying the different electronic properties of the reaction complex. This methodology has been successfully applied in a wide range of chemical reactions [15], including homogenous catalysis [16]. Another relevant approach for studying a given chemical process is the bonding evolution theory (BET) [17], which focuses on the electron pairs, as defined by the electron localisation function (ELF) topological analysis [18]. In this way, the BET enables the identification of the electronic rearrangements among the electron pairs happening along a chemical reaction; the main chemical events being characterised using
Rene Thom's catastrophe theory. The BET has also been applied to a number of chemical systems, ranging from model to complex organic reactions $[19,20]$ and also to some specific organometallic reactions, such as $\mathrm{C}-\mathrm{H}$ bond activation of methane [21], hydrogen abstraction in cytochrome P450 aromatase [22] and, more recently, the oxidative addition of ammonia $\mathrm{N}-\mathrm{H}$ bond to $\operatorname{Ir}(\mathrm{I})$ pincer complexes [23]. These studies provide a solid support to postulate 'curly arrows' schemes for the description of reaction mechanism [24]. Other approaches are based on the energy decomposition analysis and provide information related to the energetic interaction between defined fragments combined with molecular orbital analysis [25].

The latter methodology has been applied for organic molecules involved in double group transfer reactions [26]. These studies were also extended to the Noyori catalyst, with a special focus on aromaticity, strain model analysis and reaction synchronicity. For metal-ligand bifunctional catalysts, lower synchronicity and aromaticity character was observed in comparison with the organic double hydrogen transfer [27]. The origin of the reaction energy was traced to the strain energy associated with the deformation of the initial reagents. Aromatic effects are not enough to stabilise the energetic barrier, while heteroatoms in the acceptor moiety reduce the energetic barrier by the formation of hydrogen bond interactions.

In this work, a BET study on the hydrogenation of $\mathrm{C}=\mathrm{C}$ and $\mathrm{C}=\mathrm{O}$ bond of ethene and formaldehyde by a model system of the Noyori catalyst was performed. The main goals of this study are (i) identifying the sequence of chemical events taking place along the reaction pathway; (ii) determining which electronic effects strongly influence activation energies; (iii) understanding the origin of catalyst $\mathrm{C}=\mathrm{C} / \mathrm{C}=\mathrm{O}$ chemoselectivity and (iv) proposing a curly arrow diagram for the electronic rearrangement based on the BET analysis. In order to model the active catalyst, we selected the 18 electron hydride $\mathrm{RuH}\left(\mathrm{NH}_{2} \mathrm{CH}_{2} \mathrm{CH}_{2} \mathrm{NH}_{2}\right)$ ( $\eta^{6}$-benzene) see Scheme 2; the same employed by Noyori in the seminal computational paper on hydrogen transfer by metalligand bifunctional catalysts [28]. Although a change in the kinetic mechanism has been evidenced using density functional theory (DFT) calculations, from concerted (gas-phase calculations) to stepwise (inclusion of solution effects in the calculations), gas-phase calculations will be considered along this work.

\section{Computational details}

All DFT theoretical calculations were performed using the Gaussian09 programme package [29]. B3LYP method $[30,31]$ has been employed including the D3 dispersion 


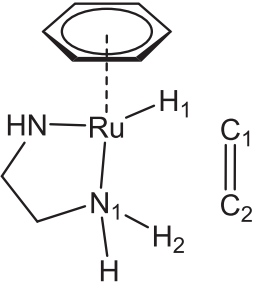

reaction $\mathbf{A}$

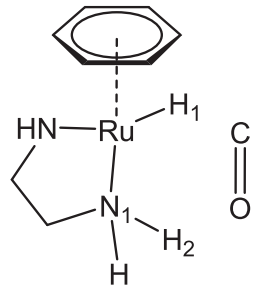

reaction $\mathbf{B}$
Scheme 2. Reactions considered in this work.

correction scheme developed by Grimme [32] using the Becke-Johnson damping [33] for both energies and gradient calculations; in conjunction with the 'ultrafine' grid. The def2-SVP basis set [34] has been selected for all atoms for geometry optimisations, performing singlepoint calculations with def2-TZVP basis set to refine energy results. The nature of the stationary points has been confirmed by analytical frequency analysis; minima and transition states were characterised by zero and one imaginary frequencies, respectively. Transition states were characterised by the calculation of reaction paths following the intrinsic reaction coordinate (force constants were calculated for each point along the reaction pathway). The ELF study was performed with TopMod programme [35] using the corresponding mono determinantal B3LYP-D3BJ/def2-TZVP wave functions in a tridimensional grid of 300 points in each direction. ELF plots were represented using the Chimera software $[3,36,37]$. The topological partition of the ELF gradient field yields basins of attractors that can be identified as corresponding to atomic cores, bonds, and lone pairs. In molecular systems, two types of basins can be found: (i) core basins surrounding nuclei and (ii) valence basins that are characterised by the number of core basins sharing the boundary, also called the synaptic order. The ELF topology depends on control space parameters, in this case, the reaction pathway as traced by following the intrinsic reaction coordinate connecting stationary points. In this way, the reaction pathway is divided into a sequence of structural stability domain (SSD) of the ELF topology, characterised by catastrophe or turning points.

\section{Results and discussion}

\section{Reaction A: BET analysis of ethene hydrogenation}

The reaction path for ethene hydrogenation by the $\mathrm{Ru}(\mathrm{II})$ hydride complex is shown in Figure 1. The activation energy is $21.3 \mathrm{kcal} \mathrm{mol}^{-1}$, and the thermodynamics of the process, defined as the energetic difference between products and reagents, is highly favourable $\left(-22.0 \mathrm{kcal} \mathrm{mol}^{-1}\right)$. The analysis of the ELF topology along the reaction path reveals a total of four SSD, namely SDD-I/IV, as depicted in Figure 1. The evolution of the most relevant ELF basin populations (the electron density integrated over the ELF basin) along the reaction pathway is reported in Figure 2. For the sake of clarity, only the basins related to the hydrogenation process are shown. As it has been previously reported in other BET studies devoted to chemical reactivity; within an SSD,

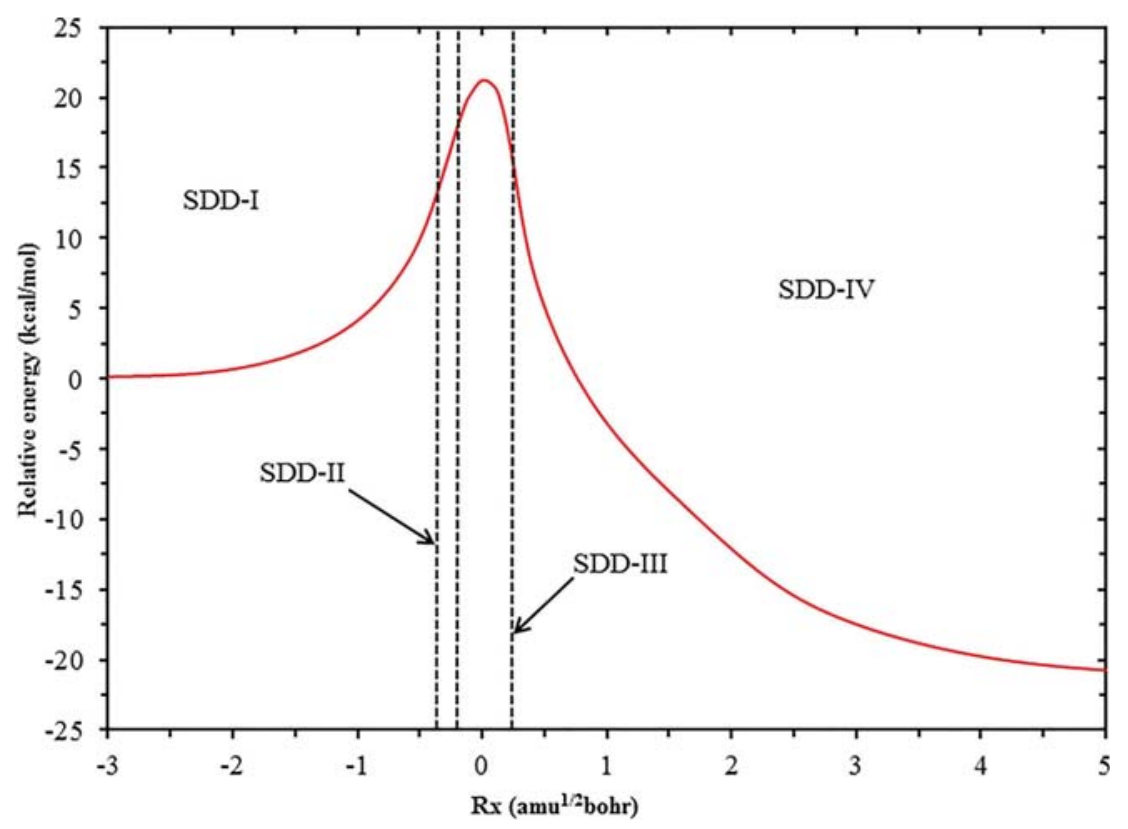

Figure 1. Energy profile for reaction A calculated at the B3LYP-D3BJ/def2-TZVP//B3LYP-D3BJ/def2-SVP level. Bifurcation points along the reaction paths are represented by lines. 


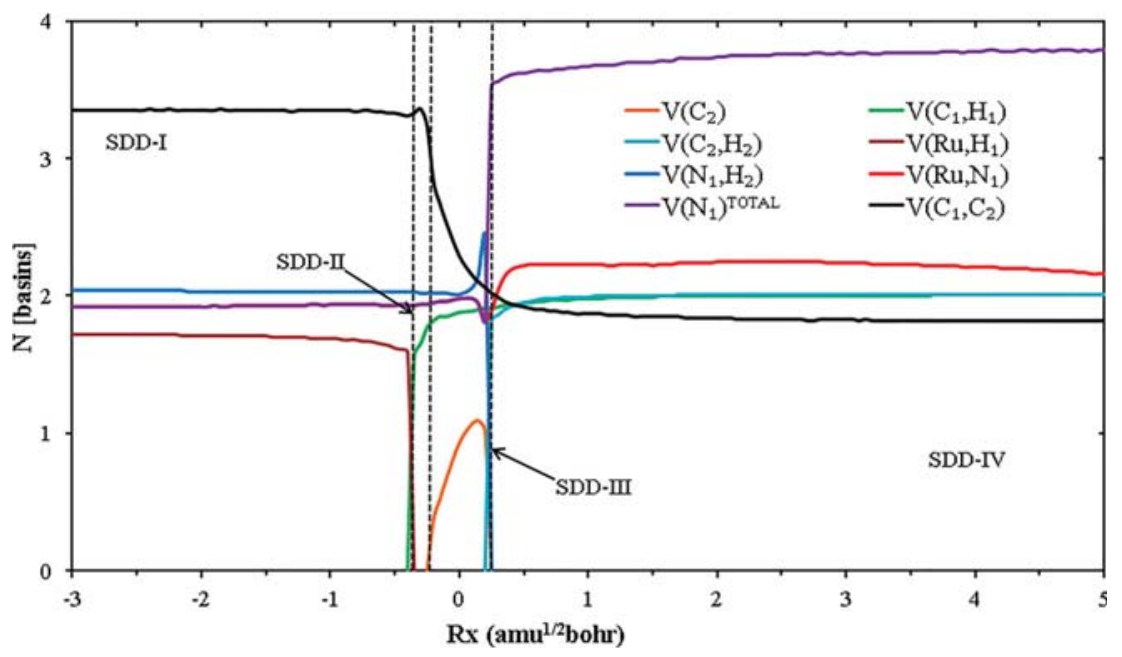

Figure 2. Integrated electron density (in electrons) for some ELF basins along the calculated IRC path for reaction A. Bifurcation points separating the SSDs indicated by vertical lines.

Table 1. Reaction coordinate ( $\mathrm{Rx}$, amu ${ }^{1 / 2}$ bohr), energy relative to the reactant at the $\mathrm{Rx}$ value (Ex, in $\mathrm{kcal}^{\mathrm{mol}}{ }^{-1}$ ), some geometrical parameters (in $\AA$ ) and selected ELF basin populations for the initial and final points of SSDs defined on the reaction path for reaction $\mathbf{A}$.

\begin{tabular}{|c|c|c|c|c|c|c|c|c|}
\hline \multirow{2}{*}{$\begin{array}{l}\text { Reaction A } \\
\mathrm{Rx}\end{array}$} & \multicolumn{2}{|c|}{ SSD-I } & \multicolumn{2}{|c|}{ SSD-II } & \multicolumn{2}{|c|}{ SSD-III } & \multicolumn{2}{|c|}{ SSD-IV } \\
\hline & -3.00 & -0.40 & -0.35 & -0.25 & -0.20 & 0.20 & 0.25 & 5.00 \\
\hline Ex & 0.0 & 12.2 & 13.5 & 16.4 & 17.9 & 17.7 & 15.2 & -20.7 \\
\hline$d R u-N_{1}$ & 2.164 & 2.117 & 2.112 & 2.103 & 2.098 & 2.067 & 2.065 & 1.962 \\
\hline$d \mathrm{Ru}-\mathrm{H}_{1}$ & 1.600 & 1.635 & 1.660 & 1.722 & 1.759 & 1.912 & 1.924 & 3.263 \\
\hline$d \mathrm{~N}_{1}-\mathrm{H}_{2}$ & 1.023 & 1.043 & 1.049 & 1.068 & 1.081 & 1.318 & 1.379 & 2.529 \\
\hline$d \mathrm{C}_{1}-\mathrm{H}_{1}$ & 2.860 & 1.621 & 1.560 & 1.438 & 1.379 & 1.199 & 1.185 & 1.101 \\
\hline$d \mathrm{C}_{2}-\mathrm{H}_{2}$ & 2.481 & 1.867 & 1.836 & 1.766 & 1.727 & 1.398 & 1.337 & 1.101 \\
\hline$d C_{1}-C_{2}$ & 1.336 & 1.361 & 1.368 & 1.387 & 1.399 & 1.456 & 1.461 & 1.527 \\
\hline $\mathrm{V}\left(\mathrm{Ru}, \mathrm{H}_{1}\right)$ & 1.72 & 1.59 & - & - & - & - & - & - \\
\hline $\mathrm{V}\left(\mathrm{Ru}, \mathrm{N}_{1}\right)+\mathrm{V}\left(\mathrm{N}_{1}\right)$ & 1.92 & 1.93 & 1.93 & 1.94 & 1.95 & 1.82 & 3.53 & 3.79 \\
\hline $\mathrm{V}\left(\mathrm{N}_{1}, \mathrm{H}_{2}\right)$ & 2.04 & 2.03 & 2.03 & 2.02 & 2.02 & 2.43 & - & - \\
\hline $\mathrm{V}\left(\mathrm{C}_{1}, \mathrm{H}_{1}\right)$ & - & - & 1.56 & 1.77 & 1.82 & 1.91 & 1.91 & 2.00 \\
\hline $\mathrm{V}\left(\mathrm{C}_{2}, \mathrm{H}_{2}\right)$ & - & - & - & - & - & - & 1.82 & 2.01 \\
\hline $\mathrm{V}\left(\mathrm{C}_{2}\right)$ & - & - & - & - & 0.37 & 1.02 & - & - \\
\hline $\mathrm{V}\left(\mathrm{C}_{1}, \mathrm{C}_{2}\right)$ & 3.35 & 3.31 & 3.33 & 3.24 & 2.83 & 2.06 & 2.02 & 1.82 \\
\hline
\end{tabular}

the number and type of ELF attractors are maintained, the bifurcation point connecting two consecutive SSDs. ELF basin populations of the initial and final points for each SSD are reported in Table 1. Moreover, the energetic variation is collected together, in conjunction with key geometrical parameters. A graphical representation of the ELF topology and populations for the reactant, transition state, and product is shown in Figure 3.

For the case of the reactant, inspection of the ELF basins corresponding to the hydrogens that are to be transferred $\left(\mathrm{H}_{1}\right.$ and $\mathrm{H}_{2}$ bonded to $\mathrm{Ru}$ and $\mathrm{N}$, respectively) reveals a lower electron population of the hydride, $\mathrm{N}\left[\mathrm{V}\left(\mathrm{Ru}, \mathrm{H}_{1}\right)\right]=1.72 \mathrm{e}$, than that of the $\mathrm{N}-\mathrm{H}$ bond, $\mathrm{N}\left[\mathrm{V}\left(\mathrm{N}_{1}, \mathrm{H}_{2}\right)\right]=2.04 \mathrm{e}$. Along the first SSD (SSD-I in Figure 1), the main changes in geometrical parameters correspond to the approximation of the carbon atoms of the olefin to the hydrogens in the catalyst. Thus, $\mathrm{dC}_{1}-\mathrm{H}_{1}$ and $\mathrm{dC}_{2}-\mathrm{H}_{2}$ distances decrease from 2.860 and 2.481 to 1.621 and $1.867 \AA$, respectively; while the electronic energy increases in $12.2 \mathrm{kcal} \mathrm{mol}^{-1}$. The analysis of ELF populations shows that $\mathrm{V}\left(\mathrm{Ru}, \mathrm{H}_{1}\right)$ decreases its population from 1.72 to $1.59 \mathrm{e}$. When $\mathrm{Rx}$ equals $-0.35 \mathrm{amu}^{1 / 2}$ bohr, a change in the ELF topology is observed and the second SSD (SSD-II) begins. In particular, the $\mathrm{V}\left(\mathrm{Ru}, \mathrm{H}_{1}\right)$ basin is transformed into a $\mathrm{V}\left(\mathrm{C}_{1}, \mathrm{H}_{1}\right)$ one through a fold-type bifurcation point.

The hydride is transferred instantaneously from $\mathrm{Ru}$ atom to $\mathrm{C}$ at a large $\mathrm{C}_{1}-\mathrm{H}_{1}$ distance of $1.560 \AA$. Interestingly, the electronic population of the newly created $\mathrm{V}\left(\mathrm{C}_{1}, \mathrm{H}_{1}\right)$ disynaptic basin, $1.56 \mathrm{e}$, comes from the former $\mathrm{V}\left(\mathrm{Ru}, \mathrm{H}_{1}\right)$ basin, $1.59 \mathrm{e}$. As a result, a negatively charged $\mathrm{CH}_{3}-\mathrm{CH}_{2}$ moiety is formed at the beginning of SSD-II. Since the hydrogen transferred from Ru to $\mathrm{C}_{1}$ carried out an electron density of $1.56 \mathrm{e}$, a total charge of $-0.56 \mathrm{e}$ can be assigned to the $\mathrm{CH}_{3}-\mathrm{CH}_{2}$ moiety. This SSD is rather short and energy increases only in $2.9 \mathrm{kcal} \mathrm{mol}^{-1}$. The formed $\mathrm{C}_{1}-\mathrm{H}_{1}$ bond increases its electron population to 

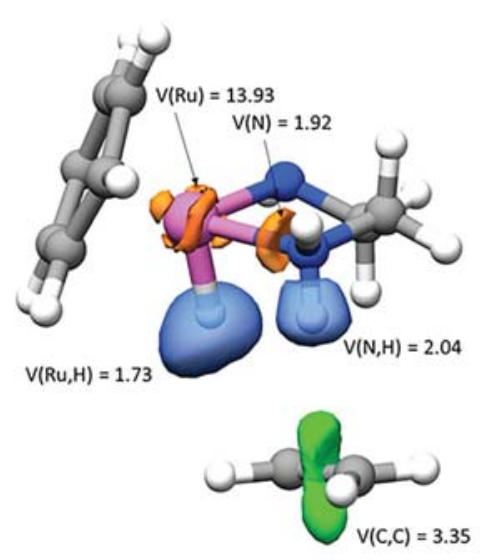
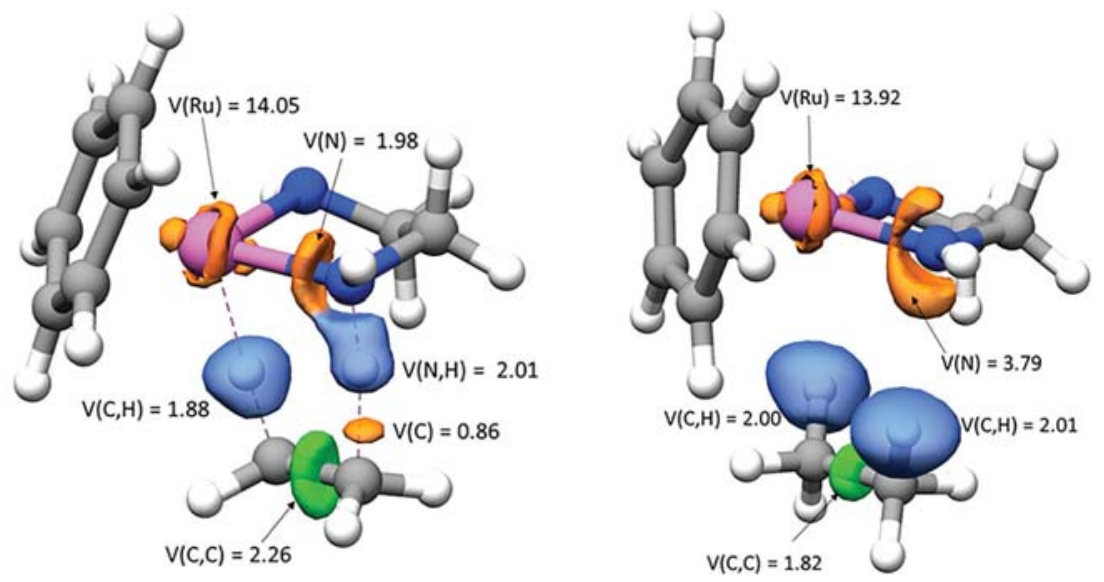

Figure 3. ELF representation of key basins for reactant (right), transition structure (middle) and product (left) for reaction $\mathbf{A}$. Isocontour value of 0.8 .

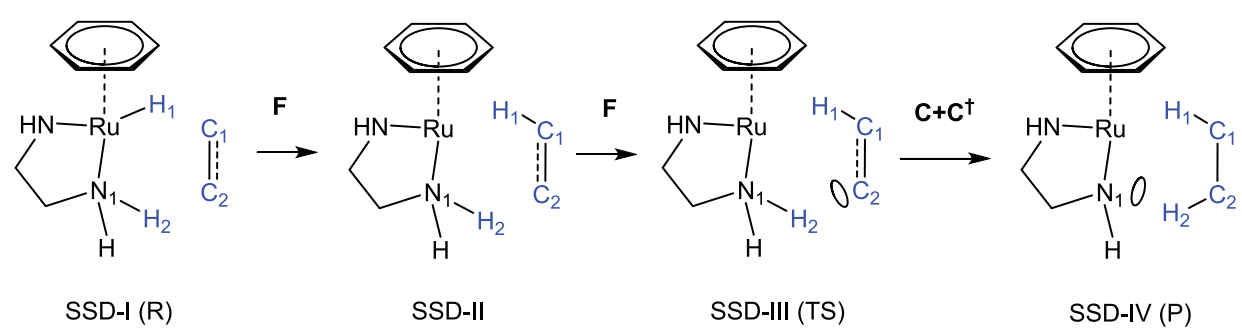

Scheme 3. Representation of changes on ELF topology for each SSD in ethene hydrogenation.

1.77e. In spite of the fact that there is no bonding ELF basin between $\mathrm{Ru}$ and $\mathrm{H}_{1}$ atoms, the interatomic distance is still too close, probably due to an agostic-type interaction between the $\mathrm{CH}$ bond and the unsaturated metal centre. The third SSD (SSD-III) involves the formation of a $\mathrm{V}\left(\mathrm{C}_{2}\right)$ monosynaptic basin from the $\mathrm{V}\left(\mathrm{C}_{1}, \mathrm{C}_{2}\right)$ one, via a fold-type bifurcation point. Along SSD-III, the electron density of the former $\mathrm{C}_{1}-\mathrm{C}_{2}$ double bond is transferred to the $\mathrm{C}_{1}-\mathrm{H}_{1}$ bond and to a monosynaptic basin at the $\mathrm{C}_{2}$ atom. At the end of this SSD, the $\mathrm{C}_{1}-\mathrm{C}_{2}$ presents an electron population of 2.06 e, close to typical values for $\mathrm{C}-\mathrm{C}$ single bonds. Noteworthy, the transition state is found at the middle of SSD-III, therefore, the total electronic energy increases first and decreases after having passed the TS. The SSD-IV starts by the formation of a V $\left(\mathrm{C}_{2}, \mathrm{H}_{2}\right)$ basin at the expense of $\mathrm{V}\left(\mathrm{C}_{2}\right)$ basin and $\mathrm{V}\left(\mathrm{N}_{1}, \mathrm{H}_{2}\right)$ conversion into $\mathrm{V}\left(\mathrm{N}_{1}\right)$. These topological changes may be explained by means of the catastrophe theory. In particular, the process would involve the merge of two bifurcation points. This way, a Cusp-type bifurcation point could convert $\mathrm{V}\left(\mathrm{N}_{1}, \mathrm{H}_{2}\right)$ into $\mathrm{V}\left(\mathrm{N}_{1}\right)$ and $\mathrm{V}\left(\mathrm{H}_{2}\right)$, being followed by a $\mathrm{C}^{\dagger}$-type bifurcation point that transforms $\mathrm{V}\left(\mathrm{C}_{2}\right)$ and $\mathrm{V}\left(\mathrm{H}_{2}\right)$ into $\mathrm{V}\left(\mathrm{C}_{2}, \mathrm{H}_{2}\right)$. Then, within this domain, the hydrogen transfer process happens, the $\mathrm{N}_{1}-\mathrm{H}_{2}$ bond is broken and the $\mathrm{C}_{2}-\mathrm{H}_{2}$ bond is formed, simultaneously.
The transferred hydrogen presents a positive charge of $+0.2 \mathrm{e}$, therefore presenting some protonic character. A schematic representation of the ELF basins and their transformations is given in Scheme 3.

\section{Reaction B: BET analysis of formaldehyde hydrogenation}

The reaction path for formaldehyde hydrogenation by the $\mathrm{Ru}$ (II) hydride complex (1) is shown in Figure 4. The activation energy is $4.4 \mathrm{kcal} \mathrm{mol}^{-1}$, considerably lower than those of reaction $\mathrm{A}$, while the thermodynamics of the process is also exothermic $\left(-14.6 \mathrm{kcal} \mathrm{mol}^{-1}\right)$. The analysis of the ELF topology along the reaction path reveals a total of three structural stability domains (SSDI/III). The population variation of some ELF basins along the reaction path is reported in Figure 5, for clarity, only the basins related to the hydrogenation process are shown. Relevant information on ELF populations, energetics, and geometrical parameters for the initial and final points for each SSD are gathered in Table 2. A graphical representation of the ELF topology and populations of the reactant, transition state, and product is shown in Figure 6. 


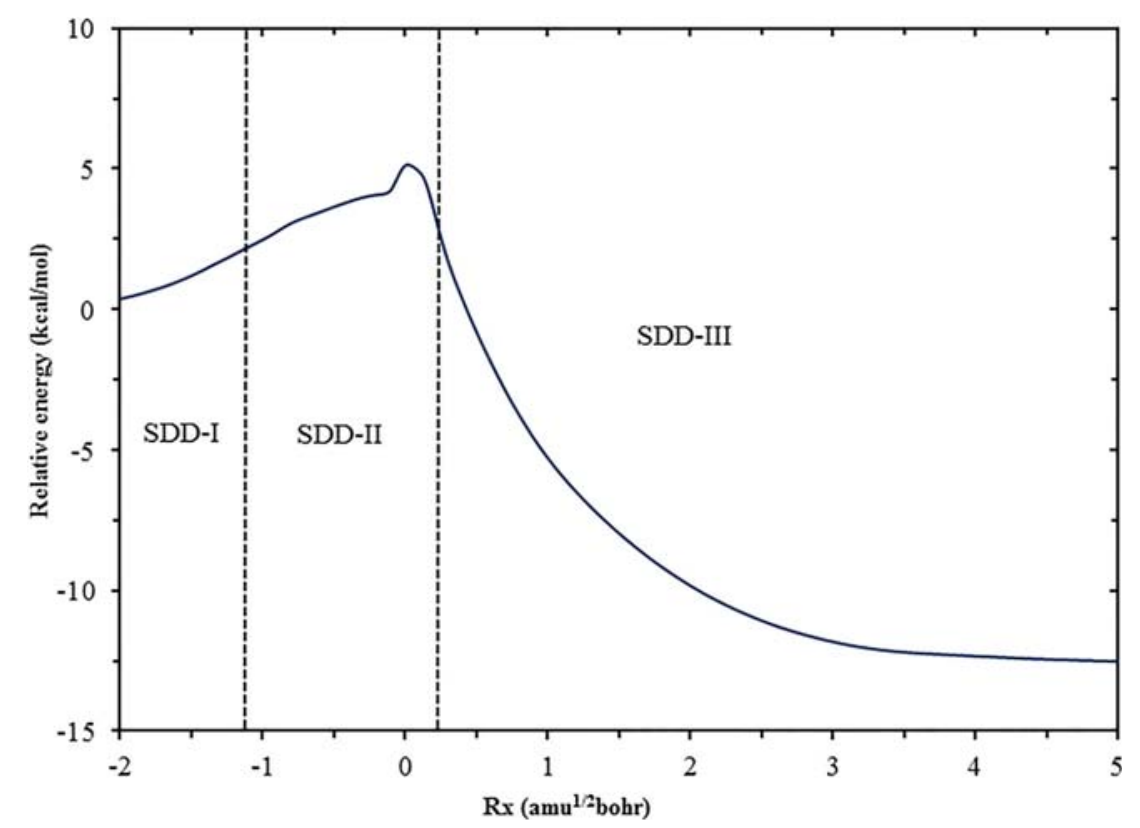

Figure 4. Energy profile for reaction B calculated at the B3LYP-D3BJ/def2-TZVP//B3LYP-D3BJ/def2-SVP level. Bifurcation points along the reaction paths are represented by lines.

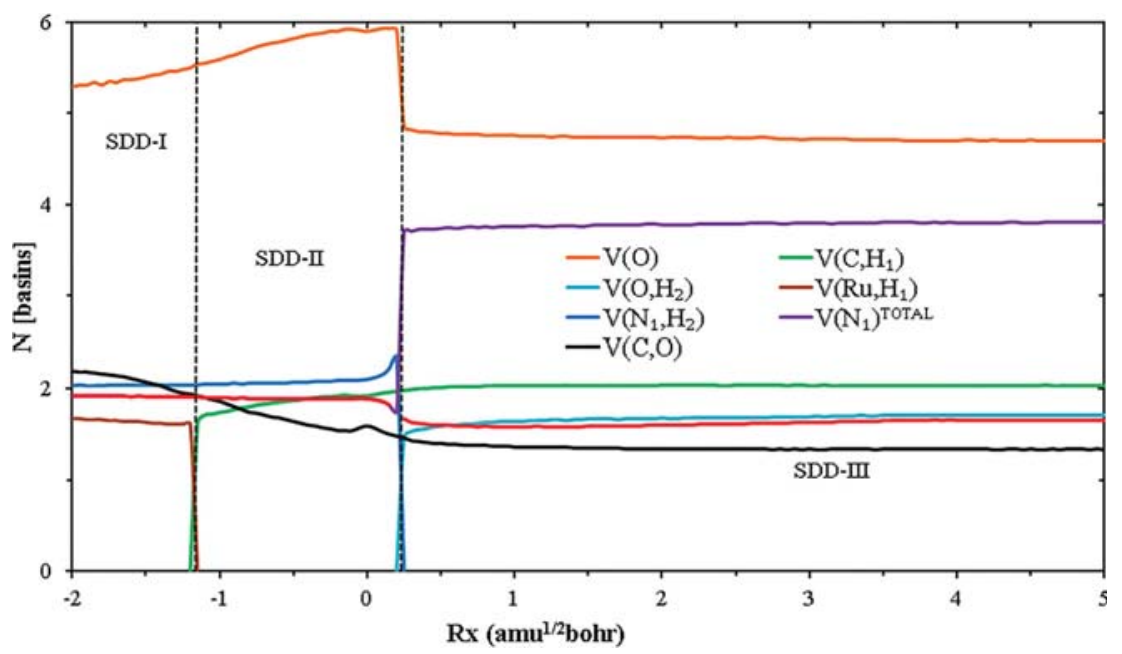

Figure 5. Integrated electron density (in electrons) for some ELF basins along the calculated IRC path for reaction B. Bifurcation points separating the SSDs indicated by vertical lines.

Even though the geometrical and ELF topological description of the metallic complex is similar to that of reaction $\mathbf{A}$; the formaldehyde presents two important differences with respect to ethene. Although in both cases $\mathrm{C}-X(X=\mathrm{C}, \mathrm{O})$ bonds are considered as double, the integrated electron population of the $\mathrm{V}(\mathrm{C}, \mathrm{O})$ basin is $2.24 \mathrm{e}$, significantly lower than the $3.35 \mathrm{e}$ of the $\mathrm{V}(\mathrm{C}, \mathrm{C})$ one. On the other hand, the oxygen lone pairs, represented by $\mathrm{V}(\mathrm{O})$ monosynaptic basins, contains a total of 5.29e. This feature is due to the higher electronegativity of the oxygen atom compared to the carbon atom, which produces a polarisation of the $\mathrm{C}-\mathrm{O}$ double bond and transferring a significant amount of electron density to the oxygen lone pairs.

The analysis of the changes along the first SSD (SSD-I) shows that the energetic increment along this domain is very low $\left(2.00 \mathrm{kcal} \mathrm{mol}^{-1}\right)$, in comparison with reaction A $\left(12.2 \mathrm{kcal} \mathrm{mol}^{-1}\right)$. Inspection of ELF basin populations reveals two major changes: $\mathrm{V}(\mathrm{C}, \mathrm{O})$ basin population decreases $0.3 \mathrm{e}$ while $\mathrm{V}(\mathrm{O})$ basin increases $0.21 \mathrm{e}$. Then, SSD-I can be characterised as a movement of electron density from $\mathrm{C}-\mathrm{O}$ bond to the oxygen lone pairs. Similarly to reaction A, the second SSD (SSDII) starts by hydrogen transfer from $\mathrm{Ru}$ to $\mathrm{C}_{1}$ in the 

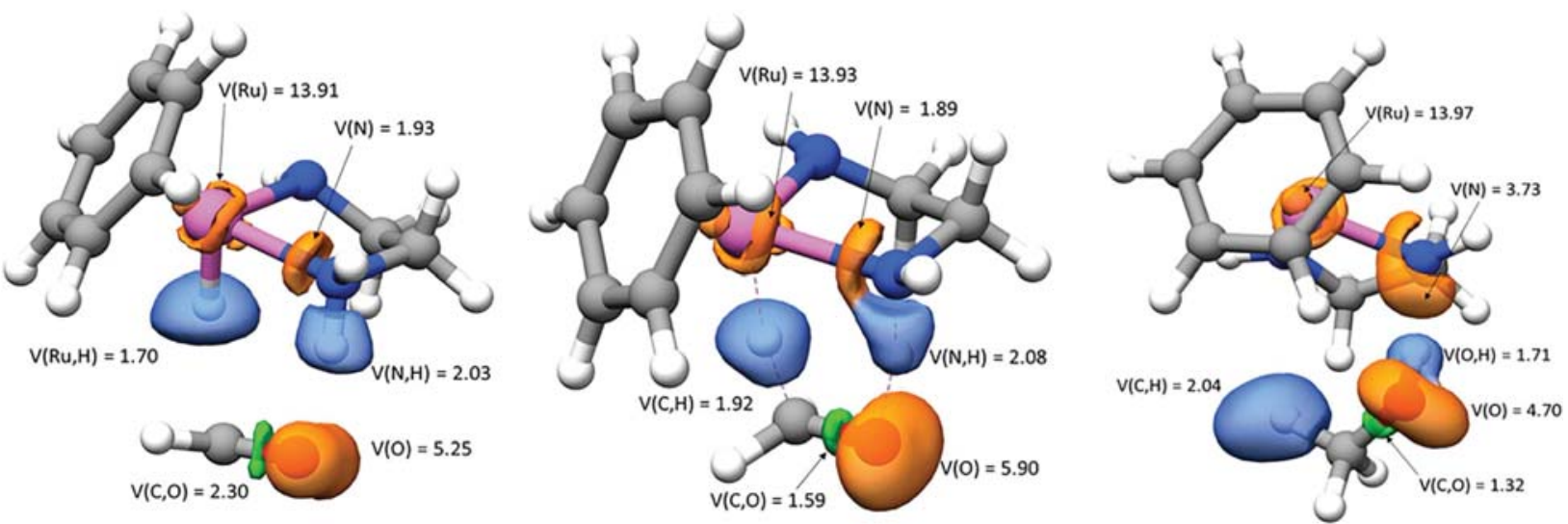

Figure 6. ELF representation of key basins for reactant (right), transition structure (middle) and product (left) for reaction $\mathbf{B}$. Isocontour value of 0.8 .

Table 2. Reaction coordinate ( $\mathrm{Rx}, \mathrm{amu} \mathrm{u}^{1 / 2}$ bohr), energy relative to the reactant at the $\mathrm{Rx}$ value (Ex, in $\mathrm{kcal}_{\mathrm{mol}}{ }^{-1}$ ), some geometrical parameters (in $\AA$ ) and selected ELF basin populations for the initial and final points of SSDs defined on the reaction path for reaction $\mathbf{B}$.

\begin{tabular}{|c|c|c|c|c|c|c|}
\hline \multirow{2}{*}{$\begin{array}{l}\text { Reaction B } \\
\mathrm{Rx}\end{array}$} & \multicolumn{2}{|c|}{ SSD-I } & \multicolumn{2}{|c|}{ SSD-II } & \multicolumn{2}{|c|}{ SSD-III } \\
\hline & -2.50 & -1.20 & -1.15 & 0.20 & 0.25 & 5.00 \\
\hline Ex & 0.0 & 2.0 & 2.1 & 3.5 & 2.6 & -12.5 \\
\hline$d \mathrm{Ru}-\mathrm{N}_{1}$ & 2.158 & 2.135 & 2.134 & 2.096 & 2.093 & 2.006 \\
\hline$d \mathrm{Ru}-\mathrm{H}_{1}$ & 1.617 & 1.672 & 1.679 & 1.963 & 1.978 & 3.418 \\
\hline$d \mathrm{~N}_{1}-\mathrm{H}_{2}$ & 1.020 & 1.034 & 1.039 & 1.280 & 1.349 & 1.792 \\
\hline$d \mathrm{C}-\mathrm{H}_{1}$ & 2.086 & 1.569 & 1.543 & 1.178 & 1.164 & 1.111 \\
\hline$d \mathrm{O}-\mathrm{H}_{2}$ & 1.935 & 1.703 & 1.687 & 1.200 & 1.131 & 0.992 \\
\hline$d \mathrm{C}-\mathrm{O}$ & 1.214 & 1.242 & 1.247 & 1.330 & 1.337 & 1.393 \\
\hline $\mathrm{V}\left(\mathrm{Ru}, \mathrm{H}_{1}\right)$ & 1.69 & 1.61 & - & - & - & - \\
\hline$V\left(R u, N_{1}\right)+V\left(N_{1}\right)$ & 1.92 & 1.91 & 1.91 & 1.75 & 3.71 & 3.81 \\
\hline $\mathrm{V}\left(\mathrm{N}_{1}, \mathrm{H}_{2}\right)$ & 2.03 & 2.04 & 2.04 & 2.34 & - & - \\
\hline $\mathrm{V}\left(\mathrm{C}, \mathrm{H}_{1}\right)$ & - & - & 1.63 & 1.97 & 1.98 & 2.03 \\
\hline $\mathrm{V}\left(\mathrm{O}, \mathrm{H}_{2}\right)$ & - & - & - & - & 1.47 & 1.71 \\
\hline $\mathrm{V}(0)$ & 5.29 & 5.50 & 5.54 & 5.91 & 4.86 & 4.70 \\
\hline $\mathrm{V}(\mathrm{C}, \mathrm{O})$ & 2.24 & 1.94 & 1.92 & 1.48 & 1.46 & 1.33 \\
\hline
\end{tabular}

double bond. The $\mathrm{V}\left(\mathrm{Ru}, \mathrm{H}_{1}\right)$ disappears while $\mathrm{V}\left(\mathrm{C}_{1}, \mathrm{H}_{1}\right)$ is formed by a fold-type bifurcation point. SSD-II ranges from $\mathrm{Rx}=-1.15$ to $+0.20 \mathrm{amu}^{1 / 2}$ bohr, thus containing the transition state. Along this domain, the transfer of electron density from $\mathrm{V}(\mathrm{C}, \mathrm{O})$ to $\mathrm{V}(\mathrm{O})$ continues. The newly created $\mathrm{V}\left(\mathrm{C}_{1}, \mathrm{H}_{1}\right)$ basin also increases its population from $1.63 \mathrm{e}$ to $1.97 \mathrm{e}$. In addition, there is a redistribution of electron density at the metallic moiety; the $\mathrm{V}\left(\mathrm{N}_{1}, \mathrm{H}_{2}\right)$ basin increasing its electron population from $2.04 \mathrm{e}$ to $2.34 \mathrm{e}$.

The third SSD (SSD-III) starts by the transformation of the $\mathrm{V}\left(\mathrm{N}_{1}, \mathrm{H}_{2}\right)$ basin into the $\mathrm{V}\left(\mathrm{C}_{2}, \mathrm{H}_{2}\right)$ one. In comparison to reaction $\mathbf{A}$, this is the same type of bifurcation point as the change from SSD-III to SSD-IV. Noteworthy, for the case of reaction $\mathbf{A}$, the intermediate formation of a monosynaptic basin, $\mathrm{V}\left(\mathrm{C}_{2}\right)$, originated a previous change on the ELF topology; this fact being the reason why reaction A presents four SSDs and reaction B only three. In the case of the oxygen atom, it already presents a monosynaptic basin corresponding to lone pairs, so there is no need for a specific SSD that creates this basin. As for reaction $\mathbf{A}$, the hydrogen transfer occurring in this step presents some proton transfer character. The $\mathrm{V}\left(\mathrm{O}, \mathrm{H}_{2}\right)$ population at the beginning of SSDIII is 1.47 e. This electron density should come from two sources: the lone pairs of the oxygen atom and the transferred hydrogen atom. As the lone pairs of oxygen, $\mathrm{V}(\mathrm{O})$, decrease the electron population from 5.91e to 4.86e (a transfer of $0.95 \mathrm{e}$ ), the electron population coming from the hydrogen being transferred should be estimated around 0.52e. A schematic representation of the ELF basins and their transformations along reaction $\mathbf{B}$ is given in Scheme 4.

\section{Comparison between reactions $A$ and $B$ : origin of $\mathrm{C}=\mathrm{C} / \mathrm{C}=\mathbf{O}$ chemoselectivity}

On the basis of the BET study, the molecular mechanism for the hydrogenation of ethene and formaldehyde by 18 electron hydride $\mathrm{Ru}$ (II) complexes can be described as (i) hydride transfer and formation of a negatively charged $\mathrm{CH}_{3}-\mathrm{X}\left(\mathrm{X}=\mathrm{CH}_{2}, \mathrm{O}\right)$ moiety; (ii) redistribution of electronic density within the $\mathrm{CH}_{3}-\mathrm{X}\left(\mathrm{X}=\mathrm{CH}_{2}, \mathrm{O}\right)$ moiety and (iii) proton transfer and formation of the lone pair at 


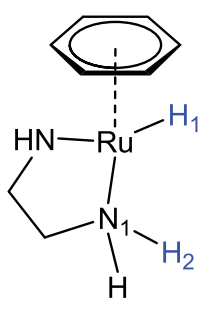

SSD-I (R)

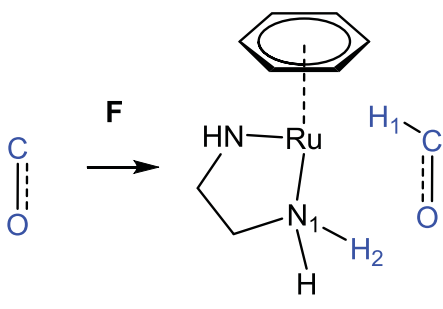

SSD-II (TS)

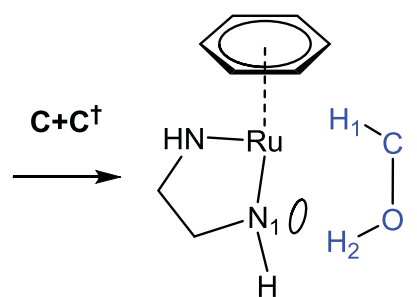

SSD-III (P)

Scheme 4. Representation of changes on ELF topology for each SSD in formaldehyde hydrogenation.

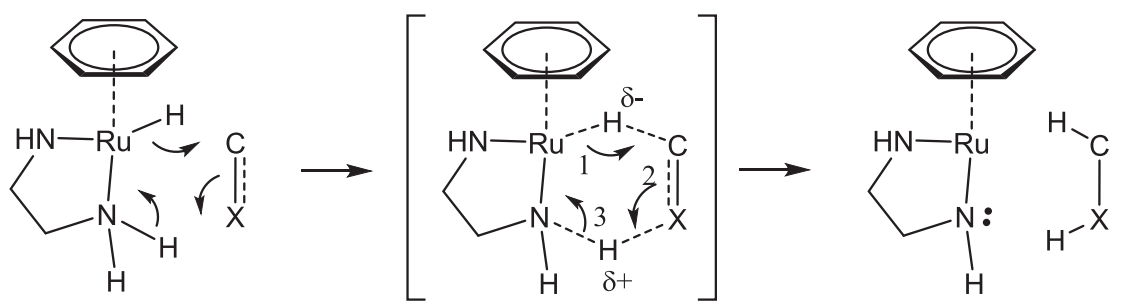

Scheme 5. Curly arrow representation of the electronic rearrangements based on BET.

nitrogen atom belonging to the catalyst. The synchronicity between both hydrogen transfers is expected to be moderate because the chemical events take place separately along the reaction path. This observation is in line with previous theoretical studies [27]. From our analysis, the hydride transfer occurs before the TS, $\mathrm{Rx}=-0.35$ and $-1.15 \mathrm{amu}^{1 / 2}$ bohr for reactions $\mathbf{A}$ and $\mathbf{B}$, respectively. On the contrary, the proton transfer happens after the TS, $\mathrm{Rx}=0.25 \mathrm{amu}^{1 / 2}$ bohr for both reactions. Therefore, lower synchronicity for the formaldehyde case is expected. The $\mathrm{CH}_{3}-\mathrm{X}\left(\mathrm{X}=\mathrm{CH}_{2}, \mathrm{O}\right)$ moiety formed along the second SSD (in both cases) can be classified as a hidden intermediate, as defined by Kraka and Cremer [38]. The hidden intermediate becomes a real intermediate if solvent effects, which can stabilise the charged species, are included in the calculations, as shown by Dub and Ikariya [11].

The origin of the energetic barrier can be traced to the hydride transfer from the metal to the unsaturated bond and formation of a negatively charged $\mathrm{CH}_{3}-X$ $\left(\mathrm{X}=\mathrm{CH}_{2}, \mathrm{O}\right)$ moiety. From the BET analysis, two facts explain the lower energetic barrier for the formaldehyde. First, the C-O double bond is polarised towards the oxygen, leaving space for the hydride transfer to the $\mathrm{C}$ atom or, in other words, the carbon atom presents an electrophilic character. Second, the oxygen atom stabilises more effectively than the $\mathrm{CH}_{2}$ group the excess of the negative charge of the $\mathrm{CH}_{3}-\mathrm{X}\left(\mathrm{X}=\mathrm{CH}_{2}, \mathrm{O}\right)$ moiety in its lone pairs.

Curly arrow representations are extremely useful in order to link acquainted chemical concepts with the subjacent quantum chemical reality. The identification of the chemical events using the BET allows to propose the curly diagram for the gas phase depicted in Scheme 5. Thus, the unveiled mechanistical insight opens the door to new synthetic routes by selectively tuning the chemoselectivity of these hydrogenations, as well as the purposeful design of novel catalysts, within a vehicular language that most synthetic chemists are comfortable with.

\section{Conclusions}

The chemical events associated with the electronic rearrangements taking place for the hydrogenation of ethene and formaldehyde using a model $\mathrm{Ru}(\mathrm{II})$ hydride complex have been analysed using BET on the basis of DFT calculations. Understanding the electronic fluxes along this chemical process provides new insights into the factors controlling the associated energetic barriers, being also a valuable tool for the design of novel catalysts with improved properties. Comparison between ethene and formaldehyde as model cases have allowed to clarify the origin of the significantly different energetic barriers that both processes present.

BET studies also revealed that for both cases, the molecular mechanism is very similar: (i) hydride transfer and formation of a negatively charged $\mathrm{CH}_{3}-\mathrm{X}$ ( $X=\mathrm{CH}_{2}, \mathrm{O}$ ) hidden intermediate; (ii) redistribution of electronic density within the $\mathrm{CH}_{3}-\mathrm{X}\left(\mathrm{X}=\mathrm{CH}_{2}, \mathrm{O}\right)$ fragment; and finally, (iii) proton transfer from the ligand. In comparison to formaldehyde, ethene hydrogenation requires an additional SSD. This SSD is absent in the case of formaldehyde since the oxygen atom already possess 
lone pairs, $\mathrm{V}(\mathrm{O})$, available to receive the proton transfer. On the contrary, the carbon atom needs to form first a $\mathrm{V}\left(\mathrm{C}_{2}\right)$ monosynaptic basin from the $\mathrm{V}\left(\mathrm{C}_{1}, \mathrm{C}_{2}\right)$ basin so that it can receive the proton from the ligand.

The first hydrogen transfer occurs before reaching the TS, while the second hydrogen transfer occurs after the TS is passed. Therefore, activation energy depends on the first process. The ELF analysis shows that the first hydrogen transferred presents some amount of negative atomic charge, therefore it can be considered a hydride transfer process. Comparison between $\mathrm{C}=\mathrm{C}$ and $\mathrm{C}=\mathrm{O}$ unsaturated bonds provides an explanation for the origin of the different reaction barriers. The carbon atom of the $\mathrm{C}=\mathrm{O}$ bond presents an electrophilic character and, then, it is activated to receive a hydride transfer from the metallic catalyst. Additionally, due to its higher electronegativity, oxygen stabilises more the negatively charged $\mathrm{CH}_{3}-\mathrm{X}\left(\mathrm{X}=\mathrm{CH}_{2}, \mathrm{O}\right)$ hidden intermediate, resulting from the hydride transfer process.

\section{Acknowledgements}

All authors gratefully acknowledge the resources from the supercomputers 'Memento' and 'Terminus', technical expertise and assistance provided by the Institute for Biocomputation and Physics of Complex Systems (BIFI) - Universidad de Zaragoza. J. M. thankfully acknowledges Spanish MECD for an FPU fellow (FPU14/06003). R. L. acknowledges ED388 for a PhD grant.

\section{Disclosure statement}

No potential conflict of interest was reported by the authors.

\section{Funding}

This work was supported by the Ministerio de Ciencia, Innovacion y Universidades [grant number CTQ2015-67366-P].

\section{References}

[1] S. Hashiguchi, A. Fujii, J. Takehara, T. Ikariya, and R. Noyori, R. J. Am. Chem. Soc. 117, 7562 (1995).

[2] A. Fujii, S. Hashiguchi, N. Uematsu, T. Ikariya, and R. Noyori, J. Am. Chem. Soc. 118, 2521 (1996).

[3] N. Uematsu, A. Fujii, S. Hashiguchi, T. Ikariya, and R. Noyori, R. J. Am. Chem. Soc. 118, 4916 (1996).

[4] J. Takehara, S. Hashiguchi, A. Fujii, S.I. Inoue, T. Ikariya, and R. Noyori, Chem. Commun. 233 (1996).

[5] Topics in Organometallic Chemistry: Bifunctional Molecular Catalysis, edited by T. Ikariya and M. Shibasaki, (Springer-Verlag, Berlin Heidelberg, 2011), Vol. 37.

[6] T. Ikariya, Bull. Chem. Soc. Jpn. 84, 1 (2011).

[7] T. Ikariya, K. Murata, and R. Noyori, Org. Biomol. Chem. 4, 393 (2006).

[8] J.S.M. Samec, J.E. Bäckvall, P.G. Andersson, and P. Brandt, Chem. Soc. Rev. 35, 237 (2006).
[9] R. Noyori, M. Yamakawa, and S. Hashiguchi, J. Org. Chem. 66, 7931 (2001).

[10] R. Noyori, and S. Hashiguchi, Acc. Chem. Res. 30, 97 (1997).

[11] P.A. Dub, and T. Ikariya, J. Am. Chem. Soc. 135, 2604 (2013).

[12] P.A. Dub, and J.C. Gordon, ACS Catal. 7, 6635 (2017).

[13] M.A. Johnson, Nat. Chem. 1, 8 (2009).

[14] W. Zou, T.M. Sexton, E. Kraka, M. Freindorf, and D. Cremer, J. Chem. Theory Comput. 12, 650 (2016).

[15] See for instance: T.M. Sexton, M. Freindorf, E. Kraka, and D. Cremer, J. Phys. Chem. A 120, 8400 (2016).

[16] See for instance: M.C. Reis, C.S. López, E. Kraka, D. Cremer, and O.N. Faza, Inorg. Chem. 55, 8636 (2016).

[17] X. Krokidis, S. Noury, and B. Silvi, J. Phys. Chem. A. 101, 7277 (1997).

[18] B. Silvi, and A. Savin, Nature. 371, 683 (1994).

[19] V. Polo, J. Andres, S. Berski, and L.R. Domingo, J. Phys. Chem. A. 112, 7128 (2008).

[20] J. Andres, P. Gonzalez-Navarrete, V.S. Safont, and B. Silvi, Phys. Chem. Chem. Phys. 19, 29031 (2017).

[21] A. S. Nizovtsev, J. Comput. Chem. 34, 1917 (2013).

[22] I. Viciano, P. Gonzalez-Navarrete, J. Andres, and S. Marti, J. Chem. Theory Comput. 11, 1470 (2015).

[23] J. Munarriz, E. Velez, M.A. Casado, and V. Polo, Phys. Chem. Chem. Phys. 20, 1105 (2018).

[24] J. Andres, S. Berski, and B. Silvi, Chem. Commun. 52, 8183 (2016).

[25] I. Fernández, and F.M. Bickelhaupt, Chem. Soc. Rev. 43, 4953 (2014).

[26] I. Fernández, F.M. Bickelhaupt, and F.P. Cossío, Chem. Eur. J. 15, 13022 (2009).

[27] O.N. Faza, C.S. López, and I. Ferdández, J. Org. Chem. 78, 5669 (2013).

[28] M. Yamakawa, H. Ito, and R. Noyori, J. Am. Chem. Soc. 122, 1466 (2000).

[29] Gaussian 09, Revision D.01, M. J. Frisch, G.W. Trucks, H.B. Schlegel, G. E. Scuseria, M.A. Robb, J.R. Cheeseman, G. Scalmani, V. Barone, B. Mennucci, G.A. Petersson, H. Nakatsuji, M. Caricato, X. Li, H.P. Hratchian, A.F. Izmaylov, J. Bloino, G. Zheng, J.L. Sonnenberg, M. Hada, M. Ehara, K. Toyota, R. Fukuda, J. Hasegawa, M. Ishida, T. Nakajima, Y. Honda, O. Kitao, H. Nakai, T. Vreven, J.A. Montgomery, J.E. Peralta, F. Ogliaro, M. Bearpark, J.J. Heyd, E. Brothers, K.N. Kudin, V.N. Staroverov, R. Kobayashi, J. Normand, K. Raghavachari, A. Rendell, J.C. Burant, S.S. Iyengar, J. Tomasi, M. Cossi, N. Rega, N.J. Millam, M. Klene, J.E. Knox, J.B. Cross, V. Bakken, C. Adamo, J. Jaramillo, R. Gomperts, R.E. Stratmann, O. Yazyev, A.J. Austin, R. Cammi, C. Pomelli, J.W. Ochterski, R.L. Martin, K. Morokuma, V.G. Zakrzewski, G.A. Voth, P. Salvador, J.J. Dannenberg, S. Dapprich, A.D. Daniels, Ö. Farkas, J.B. Foresman, J.V. Ortiz, J. Cioslowski, and D.J. Fox, (Gaussian, Inc., WallingfordCT, 2009).

[30] C.T. Lee, W.T. Yang, and R.G. Parr, Phys. Rev. B. 37, 785 (1988).

[31] A.D. Becke, J. Chem. Phys. 98, 1372 (1993). A. D. Becke, J. Chem. Phys. 98, 5648 (1993).

[32] S. Grimme, J. Antony, S. Ehrlich, and H. Krieg, J. Chem. Phys. 132, 154104 (2010). 
[33] E.R. Johnson, and A.D. Becke, J. Chem. Phys. 123, 024101 (2005).

[34] F. Weigend, and R. Ahlrichs, Phys. Chem. Chem. Phys. 7, 3297 (2005).

[35] S. Noury, X. Krokidis, F. Fuster, and B. Silvi, Comput. Chem. 23, 597 (1999).
[36] E.F. Pettersen, T.D. Goddard, C.C. Huang, G.S. Couch, D.M. Greenblatt, E.C. Meng, and T.E. Ferrin, J. Comput. Chem. 25, 1605 (2004).

[37] T.D. Goddard, C.C. Huang, and T.E. Ferrin, J. Struct. Biol. 157, 281 (2007).

[38] E. Kraka, and D. Cremer, Acc. Chem. Res. 43, 591 (2010). 